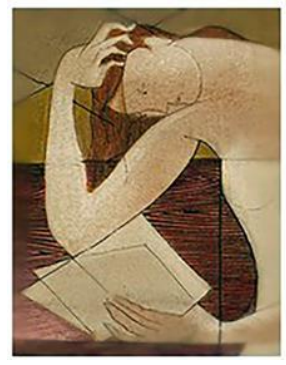

Nau Literária

crítica e teoria da literatura em língua portuguesa

PPG-LET UFRGS

ISSN 1981-4526

https://seer.ufrgs.br/NauLiteraria

Vol.16, n. 2 -2020

Dossiê Literatura e Gênero

KLEVANSKIS, Juliano. Novos fármacos \& outras histórias. Belo Horizonte: Scriptum, 2019. $247 \mathrm{p}$.

\title{
Novos fármacos, novas leituras
}

Monica Chagas da Costa

"O livro é como uma colher, tesouras, um martelo, a roda. Uma vez inventado não pode ser melhorado. Você não pode fazer uma colher melhor do que uma colher." Juliano Klevanskis

Novos fármacos \& outras histórias é o primeiro livro de contos publicado por Juliano Klevanskis, pela editora Scriptum. O livro de 2019 toma emprestado o nome de um dos contos, "Novos fármacos", para seu título. Nele, o autor retrata uma realidade distópica na qual um médico recorre aos livros como remédios para curar doenças da alma, que corroem a população acachapada por padrões rígidos de comportamento. A imagem do livro como cura, que Klevanskis faz funcionar com naturalidade, é apropriada como tom geral de um conjunto de contos que, antes de mais nada, buscam na tradição escrita sua fonte de inspiração.

Há certa progressão lógica na organização dos trinta e oito contos ao longo do livro, divididos em três partes. A primeira, composta por quinze histórias, concentra-se na reelaboração de mitos e textos da tradição judaica, além da história familiar do próprio autor. Klevanskis começa, escusada a redundância, pelo início, reimaginando a criação da humanidade a partir do relacionamento entre Lilit e Adão, no conto "Adão e Lilit no paraíso". O texto reflete sobre o papel convencional da mulher em uma tradição que a submete repetidamente a um lugar em que não pode expressar sua subjetividade, e acaba por substituíla por uma versão mais adocicada e domesticada, Eva. O mesmo tipo de questionamento se repete ao longo do livro, por vezes de forma sutil, como no conto policial "O Caso Urim Tumim", em que a inspetora Perla Vazonas se infiltra em uma seita cabalística para investigála, e passa por um rito iniciático que acaba em assassinato. Em outros casos, como o divertido “A senhora Cohen", a reflexão se dá de forma ostensiva, inserindo-se no diálogo entre netos e 


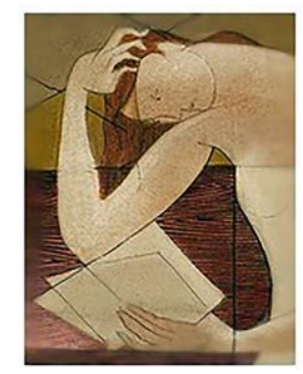

avós sobre a definição do empoderamento feminino, oferecida pela figura extremamente patriarcal do senhor Cohen.

A maior parte dos outros contos que compõem a primeira parte, "A pequena arca de gigantes", "Sodoma e Gomorra", "Naum", "Ben Sirá", "O caso dos descendentes de Lot" e "A última entrevista de Itzhak", seguem a linha de "Adão e Lilit no paraíso", ao retomarem figuras da tradição judaica e as inserirem em diferentes estruturas narrativas. $\mathrm{O}$ autor experimenta com formas do conto consagradas por grandes escritores, e, principalmente nessa primeira parte, sua maior influência parece ser Jorge Luis Borges, em especial no conto "A pequena arca de gigantes", em que o narrador remonta a história de uma família de gigantes que segue a arca de Noé em uma pequena navegação adjacente, e utiliza a linguagem acadêmica como modo de exposição da matéria ficcional. "Sodoma e Gomorra" é narrado do ponto de vista de um filho que sai das cidades perdidas, e confronta os hábitos dos pais. $\mathrm{O}$ exagero chama atenção para um puritanismo recalcado, que a ironia faz relacionar com a realidade atual. "Naum" traz a biografia do profeta judeu, concentrando-se em seu descobrimento dos mistérios da língua hebraica e dos caminhos divinos. O conto se configura, de certo modo, como uma reflexão sobre a degradação do mundo; o profeta recebe as palavras de Deus por um objeto que lembra um tablet - e esse indício reforça a ideia de que o tempo, seja presente, passado ou futuro, para Klevanskis, sempre se reencontra, como se a história fosse circular, e não linear.

Desse modo, não parece acaso que o escritor inclua no conjunto de textos iniciais seu retorno à própria história, reelaborando a memória familiar em três textos: "Uma família judia", "Uma família judia II" e "O filho do sul”. Os três contos constroem a trajetória de sua família a partir de dois eventos traumáticos na história do povo judeu - os pogroms da Rússia do final do século XIX, e a Shoah (o holocausto), provocado pelo regime nazista na primeira metade do século XX. O movimento de personalização dos eventos históricos - motores da história familiar dos Klevanskis - é também um modo de o autor amarrar os tempos presente, passado e futuro a partir da experiência individual, que desemboca nos contos finais da primeira parte. Em "Paz interior", retrata-se a realidade da população frente aos conflitos entre Israel e Palestina, retomando a ideia da convivência entre a cultura judaica e as outras que já havia sido abordada em "Ben Sirá". Por fim, em "O Homem-Água”, o escritor utiliza a 


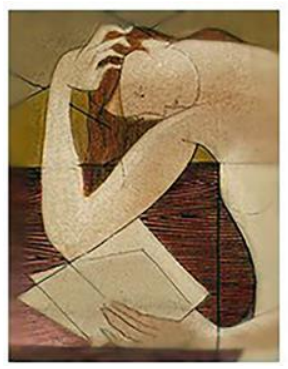

imagem do homem-água para demonstrar a evaporação do sujeito e sua precipitação por toda parte, sem deixar de carregar em si a carga de sua origem - que, no caso, é brasileira, um gancho conveniente para o grupo seguinte de textos, que se passa em sua maior parte no Brasil.

A segunda parte do livro é organizada em uma dinâmica distinta. Os quinze contos iniciais recorrem à tradição e à história para organizar as reflexões de Klevanskis sobre o lugar da escrita, do conhecimento e da pertença identitária. As dezenove histórias da segunda parte, contrastantemente, partem da realidade presente para a fantasia de um futuro por vezes distópico, de modo a compreender o lugar desses mesmos questionamentos em um mundo que parece cada vez menos aberto a se perguntar sobre si próprio. Faz sentido, portanto, que o escritor acabe por desfazer a narração realista em momentos de sonho e delírio, em que as personagens frequentemente não conseguem separar o que lhes acontece daquilo que imaginam, como no caso de "As mil e uma noites", "Setealém", "Crimes são crimes", "Medo de caixa eletrônico", "Suicídio paralelo" e "Pior, impossível”. Os mundos possíveis, sejam eles alienígenas ou espirituais, também se fazem presentes no imaginário do autor, em contos como "Estamos sozinhos?" e "Escolha sua religião".

Outra temática recorrente no segundo conjunto de contos é a violência. Seja metonimizada no corte banal de um punhado de cogumelos para um jantar em "Vem ver o seriado novo no Netflix", seja explícita no caso do tiro que soa por trás do táxi em "De repente, um tiro", seja descoberta aos poucos pelo olhar da personagem que relembra sua infância em "Combate mortal", seja estrutural como em "Depois do Natal". Parece que o autor procura refletir sobre os modos como a violência se infiltra na vida cotidiana, e as consequências que ela pode ter para o equilíbrio mental de suas personagens. É interessante, nesse contexto, sua reescrita da biografia do pensador Walter Benjamin, em "Walter", que escapa do regime nazista, se refugia em Portugal e acaba por abandonar a filosofia como modo de sobrevivência, em uma resposta pouco esperada ao mundo de violência que o produz e aniquila.

O principal tema, contudo, nos contos de Klevanskis, continua sendo a escrita, seja como criação, como leitura, ou como forma de conhecimento do mundo. "A arte de pedir um livro em uma livraria" olha para o livro ao mesmo tempo como produto e como ponte de 


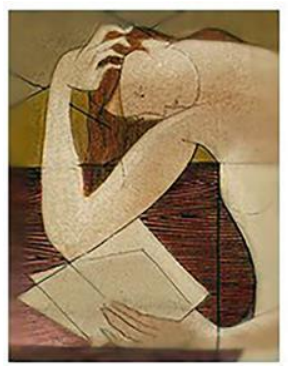

ligação entre as personagens que entram em contato com o livreiro. Em "A duas mãos", a escrita é lugar de encontro entre duas pessoas desconhecidas, que traçam o destino uma da outra, de um lado através da pesquisa sobre o Efeito Borboleta, de outro a partir da ficção. Ao estilo de Quiroga, a ficção salta da página e volta para a assombrar a realidade. "Os tipógrafos", por sua vez, acena para as mudanças tecnológicas que influenciam a vida dos trabalhadores envolvidos nos processos de produção da literatura, e que acabam por cair na obsolescência. Finalmente, em "Novos fármacos", como já mencionado, o escritor expande a capacidade curativa da leitura a uma realidade em que o livro se torna motivo de vergonha e estranheza, e na qual a leitura é uma idiossincrasia. A imaginação de Klevanskis exagera aspectos da realidade atual e os distorce em novos mundos, cheios de opressão, que prenunciam um futuro possível, para o qual parece sugerir como provável remédio a leitura.

O escritor fecha seu volume de contos com quatro histórias, "A gênese dos cães", "Gato Borges”, "Mundo-cão" e "O caçador". Ao voltar-se para a condição animal, ele acena para uma tradição brasileira de contos fantásticos, e procura refletir sobre as proximidades entre a experiência dos homens e dos bichos. Os cães e gatos servem de imagem na qual o autor reconhece diferentes traços de humanidade - sejam eles positivos ou não.

A obra de Juliano Klevanskis parece ser uma tentativa de congregar os temas da escrita, da violência, da tradição judaica, da religião em geral e do tempo em formas que homenageiam e atualizam a história da literatura. Fazem-se presentes Jorge Luis Borges, Edgar Allan Poe, Machado de Assis, Murilo Rubião, entre outros nomes consagrados, na composição do remédio que o autor nos oferece através de suas pequenas histórias. Seus fármacos sustentam-se nos ombros de gigantes, como os que encontramos seguindo a arca de Noé, e apontam para os problemas que encontramos na realidade atual, levando em consideração tanto uma tradição histórica e literária consolidada, como futuros imaginados a partir de elementos atuais. 